\title{
Implementation of a viscoplastic substrate creep model in the thermomechanical simulation of the WAAM process
}

\author{
S. Springer ${ }^{1} \cdot$ A. Röcklinger ${ }^{1} \cdot$ M. Leitner ${ }^{2} \cdot$ F. Grün ${ }^{1} \cdot$ T. Gruber $^{3} \cdot$ M. Lasnik ${ }^{3} \cdot$ B. Oberwinkler $^{3}$
}

Received: 23 August 2021 / Accepted: 2 December 2021 / Published online: 11 December 2021

(c) The Author(s) 2021

\begin{abstract}
This research work focusses on the implementation of a viscoplastic creep model in the thermomechanical simulation of the wire arc additive manufacturing (WAAM) process for Ti-6Al-4 V structures. Due to the characteristic layer by layer manufacturing within the WAAM process, viscoplastic material effects occur, which can be covered by implementing a creep model in the thermomechanical simulation. Experimental creep tests with a wide temperature, load and time range were carried out to examine short-term creep behaviour in particular. A Norton-Bailey creep law is used to accurately fit the experimental data and describe the base material's creep behaviour. Subsequently, the fitted Norton-Bailey creep law was implemented in the thermomechanical simulation of the WAAM process. Finally, to determine the effect of creep on global distortion and local residual stress state in the substrate, simulations of a simplified linear, three-layer WAAM structure, with and without applying the implemented creep law, were carried out and compared to experimental data. The thermomechanical simulation with implemented creep model reveals a significant improvement in the numerical estimation of distortion and residual stress state in the substrate. The maximum distortion is reduced by about $13 \%$ and respectively the mean absolute percentage error between simulation and experiment decreases by about $34 \%$. Additionally, the estimation accuracy with respect to the local residual stress state in the substrate improved by about $10 \%$.
\end{abstract}

Keywords Thermomechanical simulation · Additive manufacturing $\cdot$ WAAM $\cdot$ Viscoplastic model $\cdot$ Ti-6Al-4 V

\section{Introduction}

Additive manufacturing (AM) represents an innovative technology for a time- and cost-efficient production of geometrically complex components and structures. In addition to already established powder-based additive manufacturing processes, such as selective laser melting, wire-based AM technologies are available, especially for large structures [1-3]. One AM technology used for large, medium complex structures is wire arc additive manufacturing, in which the wire is fed as base material, melted by means of an electrical arc and additively added layer by layer on a substrate. The

S. Springer

sebastian.springer@unileoben.ac.at

1 Montanuniversität Leoben, Chair of Mechanical Engineering, Leoben, Austria

2 Institute of Structural Durability and Railway Technology, Graz University of Technology, Graz, Austria

3 Voestalpine BÖHLER Aerospace GmbH \& Co KG, Kapfenberg, Austria process is of interest to the aerospace industry in particular, due to its lightweight design and buy-to-fly optimization potential, using the titanium alloy Ti-6Al-4 V [4-6]. Another advantage of using WAAM for large parts is to build hybrid parts, where semi-finished products are used as base and the final part consists of the remaining substrate or base material $[7,8]$. In addition to the advantages of the WAAM process, there are technological challenges that are currently under research. These challenges are, for example, process stability, component design, path planning strategies or the formation and prediction of residual stresses and distortion in the WAAM process $[9,10]$. The latter has a significant influence on the quality of the manufactured components and a minimization of residual stresses and distortion in the substrate should be achieved [11, 12].

In order to optimize the WAAM process, extensive parameter studies are crucial, whereby thermomechanical process simulation can be used as a simulation tool, thus reducing development time and cost [5, 13]. Different numerical methods are available for efficient estimation of the resulting residual stresses and deformations, whereby thermomechanical 
finite element welding simulation is commonly used for the WAAM process simulation $[14,15]$. Thermomechanical simulation represents a possibility to investigate, evaluate and characterize the influence of different thermal, geometric or process parameters on distortion and residual stress occurring within the WAAM process [16, 17].

Studies focusing on validation and calibration of thermomechanical process simulation with experimental data of additive manufacturing processes reveal an overestimation regarding simulated distortion and residual stress [18, 19]. Further investigations in $[20,21]$ showed that the overestimation in simulation is ascribed to a simplification according to the non-implementation of viscoplastic material behaviour, like creep or stress relaxation. Due to the characteristic layer by layer manufacturing, previous additively manufactured layers are heated up again while manufacturing the following layers. The combination of thermal (heat input) and mechanical load (residual stress in the structure) lead to viscoplastic effects during additive manufacturing processes. In order to capture viscoplastic effects in the thermomechanical simulation of the WAAM process, methods with the implementation of stress relaxation are presented in [22-24]. Furthermore, a study in [25] presents the influence and effect of stress relaxation, due to transformation strains, on the simulated distortion of Ti6Al-4 V and nickel alloy structures, whereby the simulation error is reduced majorly by the definition of a stress relaxation temperature and setting plastic strain to zero above this temperature. In contrast to stress relaxation, no simulation model with an explicitly implemented creep behaviour, to describe the occurring viscoplastic effect during the WAAM process, is found in the literature. Hence, this study focusses on the implementation and the effect of creep material behaviour in wire arc additive manufacturing. The scientific contribution can be specified as follows:

- Presentation of a methodology for the development, implementation and validation of a creep model in the simulation of the WAAM process, by focussing on the characterization of the base material and validation with the substrate.

- Extensive characterization of creep behaviour with creep tests in a wide temperature and stress range for material out of a Ti-6Al-4 V plate.

- Implementation of a Norton-Bailey creep model [26, 27] for the thermomechanical simulation of the WAAM process based on the experimental creep test results for material out of a substrate.
- Validation of creep model implementation by comparison of simplified creep test simulation with experimental data.

- Comparison of simulated distortion and residual stress state in the substrate with measured data for a three-layer WAAM structure to assess the impact of implementing the viscoplastic creep material behaviour.

\section{Experimental}

\subsection{Creep tests}

Viscoplastic material behaviour-in particular creep-is strongly depending on materials manufacturing history. Therefore, all creep test specimens were manufactured out of a Ti-6Al-4 V sheet with a thickness of about $12.4 \mathrm{~mm}$, which is used as substrate for the WAAM process in this study. The material condition of base plate material was conventionally processed by hot-rolling. The nominal chemical composition of the Ti-6Al-4 V base and wire material is shown in Table 1. In Table 2, the nominal mechanical properties of the base material after solution heat-treatment and the melting temperature are provided. Preliminary static tensile tests of base material reveal comparable values to the provided nominal mechanical properties.

Basically, creep tests were carried out in accordance with the ASTM E139 standard [31]. The dimensions of the specimens were primarily defined to obtain samples out of the substrate. Additionally, the specimen's geometric dimensions are optimized regarding a homogeneous temperature field in the testing area for the high-temperature creep tests. Cylindrical specimens with a length of $73 \mathrm{~mm}$ and a clamping diameter of $12 \mathrm{~mm}$ are utilized for creep tests. The testing area in the middle of the specimen is defined with a diameter of $5 \mathrm{~mm}$ and a length of $20 \mathrm{~mm}$. In Fig. 1, the dimensions of the investigated creep specimen are shown.

For creep tests, a uniaxial, servo-hydraulic cylinder with a maximum load capacity of $25 \mathrm{kN}$ was used. The elaborated

Table 2 Nominal physical and mechanical properties at room temperature, comparable to [28] and [30]

\begin{tabular}{llll}
\hline $\begin{array}{l}\text { Melting tempera- } \\
\text { ture } \mathrm{T}_{\text {melt }}\end{array}$ & $\begin{array}{l}\text { Proof strength } \\
\mathrm{R}_{\mathrm{p} 0.2 \%}\end{array}$ & $\begin{array}{l}\text { Tensile strength } \\
\mathrm{R}_{\mathrm{m}}\end{array}$ & $\begin{array}{l}\text { Modulus of } \\
\text { elasticity E }\end{array}$ \\
\hline $1604-1660{ }^{\circ} \mathrm{C}$ & Min. $828 \mathrm{MPa}$ & $900-950 \mathrm{MPa}$ & $110 \mathrm{GPa}$ \\
\hline
\end{tabular}

Table 1 Nominal chemical composition in weight $\%$, comparable to $[28,29]$

\begin{tabular}{lllllllll}
\hline & $\mathrm{Al}$ & $\mathrm{V}$ & $\mathrm{Fe}$ & $\mathrm{O}$ & $\mathrm{N}$ & $\mathrm{C}$ & $\mathrm{H}$ & $\mathrm{Ti}$ \\
\hline Substrate & $5.50-6.75$ & $3.50-4.50$ & $<0.30$ & $<0.20$ & $<0.05$ & $<0.08$ & $<0.015$ & Balance \\
Wire & 6.00 & 4.00 & $<0.15$ & 0.18 & $<0.03$ & $<0.05$ & $<0.01$ & Balance \\
\hline
\end{tabular}




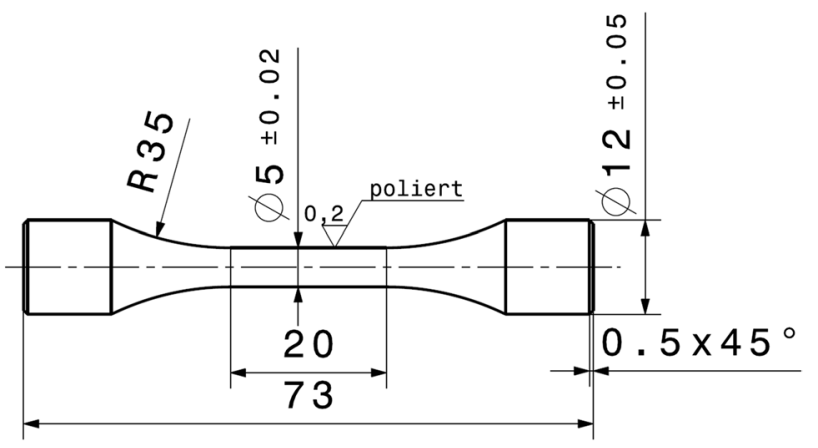

Fig. 1 Specimen geometry for creep tests

test setup is presented in Fig. 2 (left). Specimens are clamped on both ends with a cooled, hydraulic clamping system. To enable creep tests under elevated or high temperatures, the specimens are heated by optimized induction coils. Five type $\mathrm{K}$ thermocouples, distributed over the test area, are used for temperature monitoring and control during high temperature creep tests (see Fig. 2 (right)). As mentioned before, the focus laid on distributing a homogenous temperature field in the testing area.

A creep test starts with heating up the specimen to the required temperature, achieving a homogeneous temperature distribution across the test area. A tension load is applied by a ramp function within one second and is kept constant to obtain the desired stress level. Throughout the creep test, temperature and tension load are maintained constant and creep strain is measured using a touching ceramic extensometer, which has an initial length of $12.6 \mathrm{~mm}$. As the focus is on short-term creep, tests are interrupted after one hour or when failure of the specimen occurs.

To create an elaborate test matrix, a thermomechanical simulation model (without implemented creep model) of a three-layer WAAM structure was investigated, considering the occurring temperature and equivalent stress at representative positions in the WAAM structure. Therefore, two exemplary positions in the contact region between the substrate and the WAAM structure are chosen (see Fig. 3). Both analyzed positions are in half-length of trajectories longitudinal direction; one point is in the middle and one on the outer side of the WAAM structure.

Equivalent stress and temperature during the process at the defined points were considered as a function of time. Figure 4 shows the stress-temperature curve depending on simulation increments and the flow limit of the

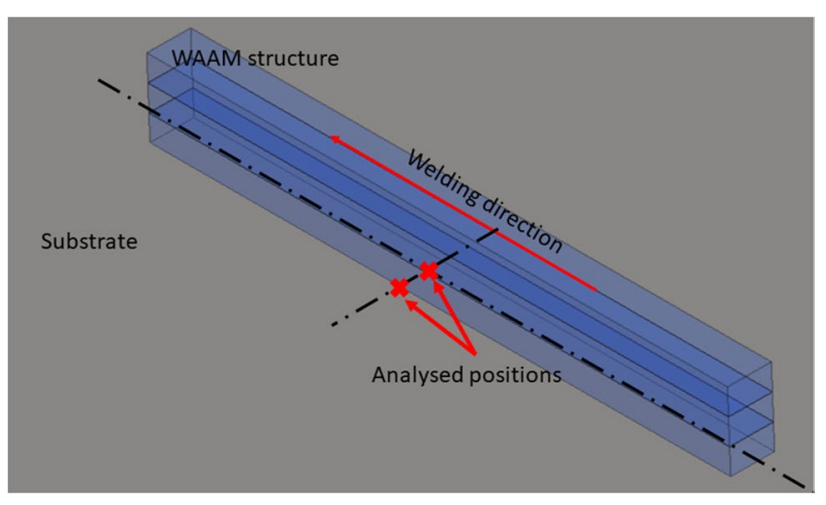

Fig. 3 Position of analyzed points in the first layer of the WAAM structure
Fig. 2 Experimental test setup (left) and detailed view on high temperature creep test (right)
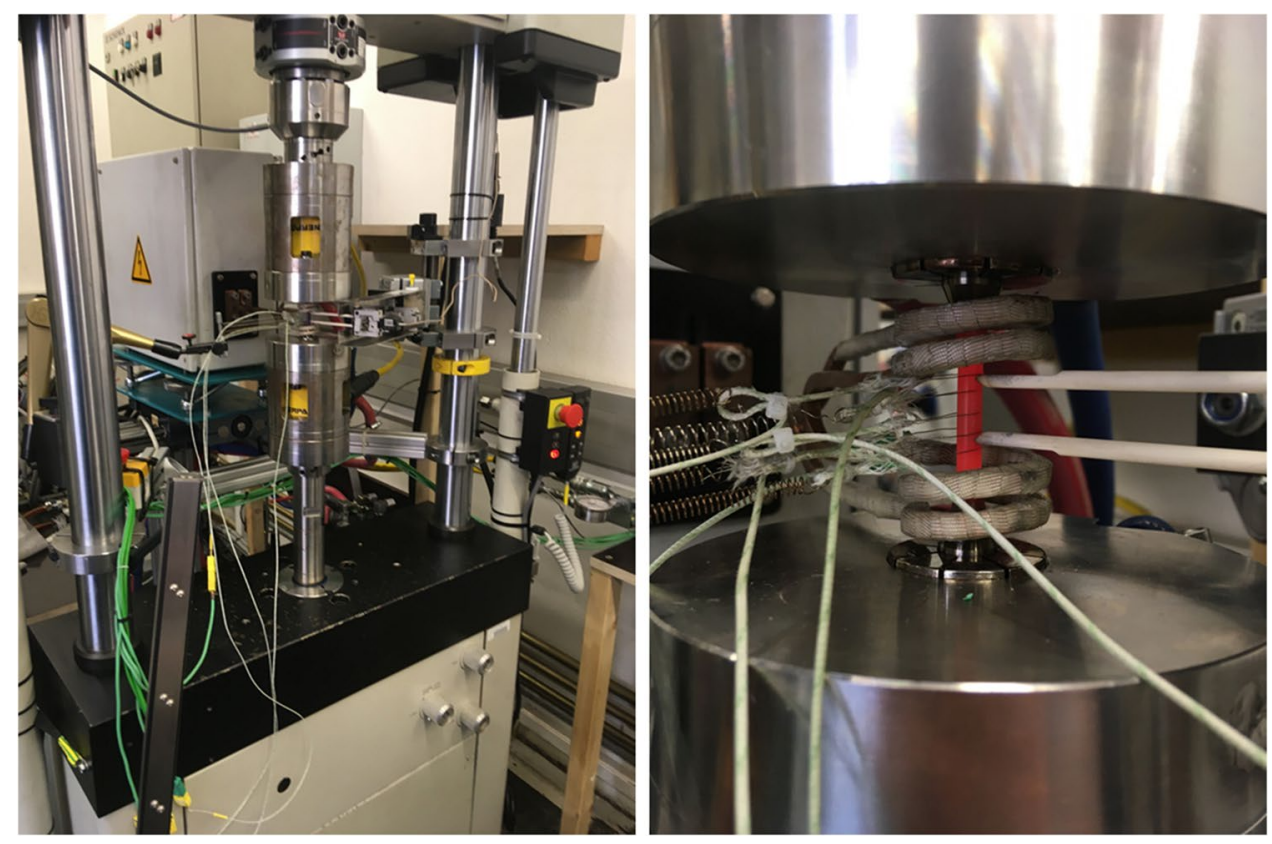


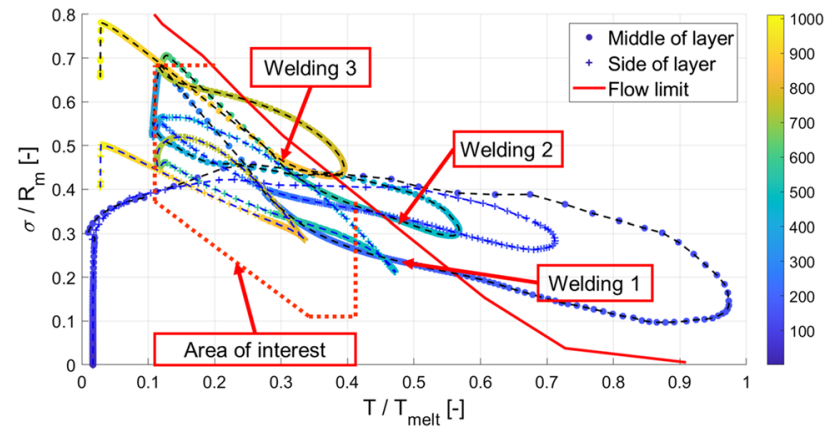

Fig. 4 Normalized temperature and stress range during the WAAM process

implemented material model in Simufact Welding for zero plastic strain. Thereby, the equivalent stress is normalized with the nominal ultimate tensile strength of the base material given by [30] and the temperature is normalized with the melting temperature given by [28].

In Fig. 4, the area outlined in red marks the area of interest for the creep tests. This area was chosen because the equivalent stress and temperature are in a range where creep is to be expected to a technically relevant extent. Within this area of interest, ten stress $\left(\sigma_{1}-\sigma_{10}\right)$ and eight temperature levels $\left(\mathrm{T}_{1}-\mathrm{T}_{8}\right)$ for the static creep tests were defined. The flow limit of the material limits the test matrix in higher stress and temperature regions. Table 3 presents the entire test matrix with the normalized stress and temperature levels, whereby the performed creep tests are marked with crosses. In total, 30 creep tests with constant stress and temperature levels were carried out.

\subsection{WAAM process and measurements}

In order to validate the simulation, with and without implementation of creep, a linear three-layer wall was welded to produce experimental data. The used base plate is a Ti-6Al-4 V plate in total $250 \mathrm{~mm}$ long, $150 \mathrm{~mm}$ wide and $12.4 \mathrm{~mm}$ thick. Four thermocouples (TC) type K $(0.50-\mathrm{mm}$ diameter) for in situ temperature measurements and four strain gauge (SG) rosettes with two measuring grids each (HBM type RC) for in situ strain/stress measurements were applied. Thermocouples were used for thermal validation of the simulation model and for thermal compensation of strain gauges. Therefore, TCs were applied at the same positions as the strain gauges but on the opposite side of the substrate (see Fig. 5). Due to the limited operating temperature of about $250{ }^{\circ} \mathrm{C}$ of the SGs, the SGs and thermocouples are placed at a slight distance from the WAAM structure. Figure 5 shows the schematic drawing (left) of substrates dimensions and the positions of TCs and SGs. Additionally, the prepared substrate is shown in Fig. 5 (right).

The WAAM process was performed using a Fronius Cold Metal Transfer (CMT) welding machine in combination with a Yaskawa Motoman welding robot and the weld pool was protected by a trailing shield purged with $99.9999 \%$ pure Argon. In Table 4, the process parameters for the manufacturing of the three-layer WAAM wall are listed. The linear WAAM wall was welded in the middle of the substrate with finally measured, total dimensions of $104.1 \mathrm{~mm}$ in length, $7.5 \mathrm{~mm}$ in width and $13.5 \mathrm{~mm}$ in height.

Before and after the WAAM process, residual stress analysis is performed in longitudinal and transversal direction, whereby longitudinal is in welding direction and transversal is normal to the welding direction. Measurements are conducted at the backside of the substrate with X-ray diffraction using a X-RAYBOT from MRX-RAYS. For the measurements, a $\mathrm{Cr}-\mathrm{K} \alpha$ radiation tube was used with a collimator
Table 3 Creep test matrix based on simulation results

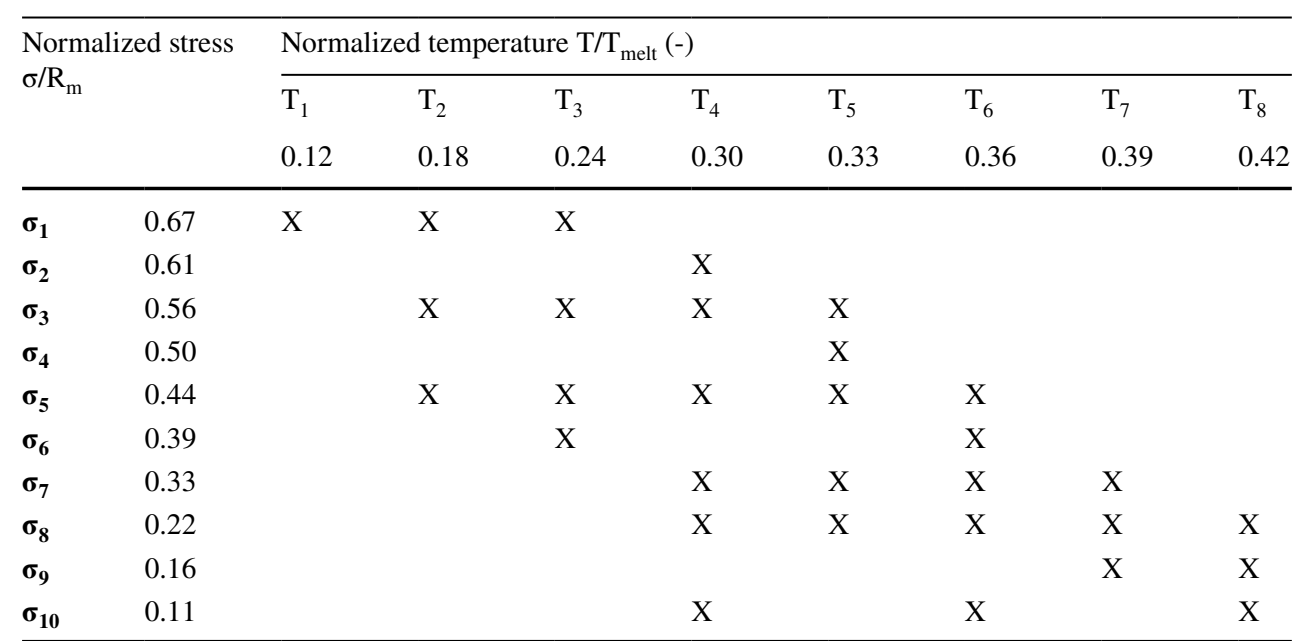



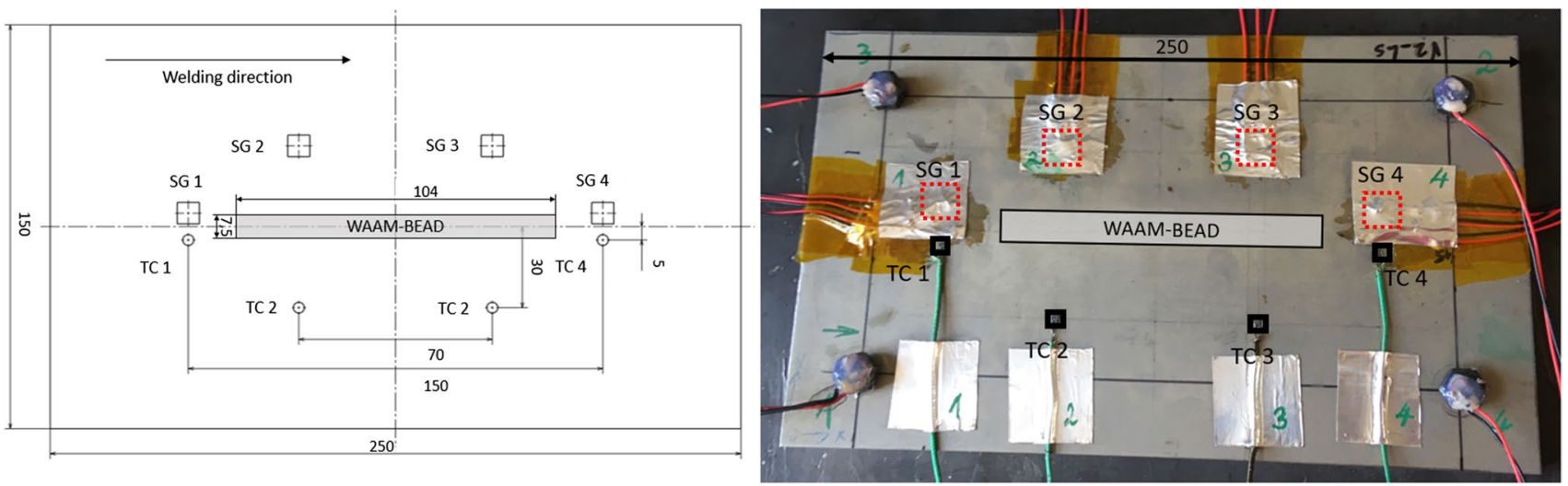

Fig. 5 Schematic (left) dimension of plate, position of thermocouples (TC) and location of strain gauges (SG) and prepared substrate (right)

Table 4 Used WAAM welding parameters

\begin{tabular}{llr}
\hline Process parameter & Unit & Value \\
\hline Current & $\mathrm{A}$ & 92.0 \\
Voltage & $\mathrm{V}$ & 18.1 \\
Travel speed & $\mathrm{mm} / \mathrm{s}$ & 2.5 \\
Wire feed speed & $\mathrm{m} / \mathrm{min}$ & 5.0 \\
Wire diameter & $\mathrm{mm}$ & 1.2 \\
\hline
\end{tabular}

diameter of $3 \mathrm{~mm}$. Moreover, in situ strain measurement was done by applying strain gauges, whereby stress was calculated by multiplying strain with the material's modulus of elasticity $E$. Additionally, Z-distortion measurements are done after unclamping on the front side of the substrate using a coordinate measuring device. The Z-distortion was evaluated along in longitudinal direction, at about eleven measurement points.

\section{Viscoplastic substrate creep model}

In order to create or fit the selected creep model to the experimental data, a data post-processing was carried out in the first step. To obtain a creep curve from the measurement results, the measured displacement with the extensometer first has to be converted into a strain. Therefore, strain is obtained by dividing the displacement signal by the initial length of the extensometer and subtracting the initial strain. Figure 6 presents a representative creep curve, where the blue curve represents the experimentally determined creep strain. Due to the partially large scatter of the experimental data, which occurred especially at low stresses due to test machine control inaccuracies, the experimental data were smoothened by using a Savitzky-Golay filter, resulting in the red curve in Fig. 6.

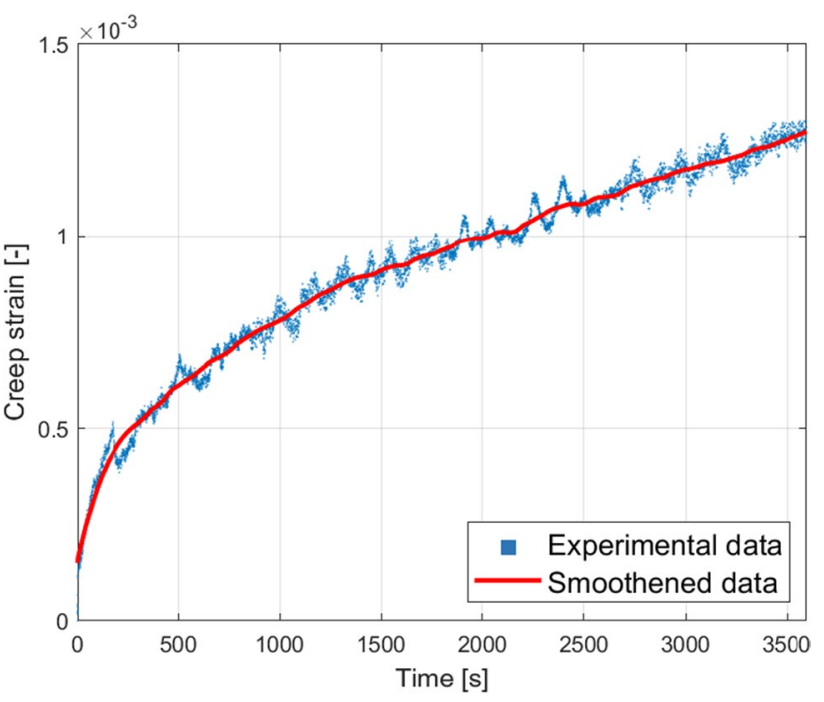

Fig. 6 Representative creep curve for creep test $\sigma_{5} / \mathrm{T}_{3}$

The smoothed data of all creep curves can then be used for the fit of the postulated creep model. An extensive regression analysis is carried out to approximate and, respectively, to fit the experimental data. All following regression steps were performed using the least-squares method. Due to the characteristic layer-by-layer manufacturing within the WAAM process and the associated short, thermo-mechanical loading of the previous layers, primarily short-term creep behaviour is relevant. Therefore, a creep law according to Norton and Bailey $[26,27]$ is chosen, which depicts the materials primary creep strain behaviour $\epsilon_{c r}$ as a function of stress $\sigma$, temperature $T$ and creep time $t$ (see Eq. (1)). The constant $A$, the stress exponent $n$ and the time exponent $m$ take the temperature dependency into account.

$\epsilon_{c r}=A \cdot \sigma^{n} \cdot t^{m}$ 
In the first step, the Norton-Bailey creep model is fitted to the experimental data for constant temperatures in order to be able to cover and approximate the temperature dependency in the next step. For the evaluation of the constant $A$ and the exponents $n$ and $m$, May et. al. [32] reported a method using a two-stage exponential regression analysis according to the method of least squares. First, the time exponent $m$ is determined, and in a further, subsequent regression the stress exponent $n$ and the constant $A$ are calculated. By applying this method to the experimental creep curves, the coefficients could be determined for constant temperatures. In Fig. 7, the fitted Norton-Bailey creep models for different temperature levels are presented as surfaces. Additionally, creep curves which were determined at the corresponding temperatures are shown in Fig. 7.

Looking at the fitted models at a specific time, the dependence of creep strain on stress can be observed (cf. Figure 8). The models with a higher temperature $\left(\mathrm{T}_{4}, \mathrm{~T}_{6}\right.$ and $\mathrm{T}_{8}$ ) reveal roughly the same stress dependence, while at lower temperatures $\left(T_{2}\right.$ and $\left.T_{3}\right)$ higher stress exponents occur. This increase of the stress exponent indicates a change in the material's creep mechanism at lower temperatures. Additionally, the comparison of the fitted creep curves for constant temperature levels, with the experimental data shows a sound correlation.

In order to capture the temperature dependence of the used Norton-Bailey creep model for Ti-6Al-4 V, a simplified approach was chosen. The creep law according to Eq. (1) is extended by a temperature-dependent function $f(T)$ and a regression analysis is done with constant values $n$ and $m$ (see Eq. (2)). The constant stress exponent $n$ is obtained by averaging the exponents from creep models

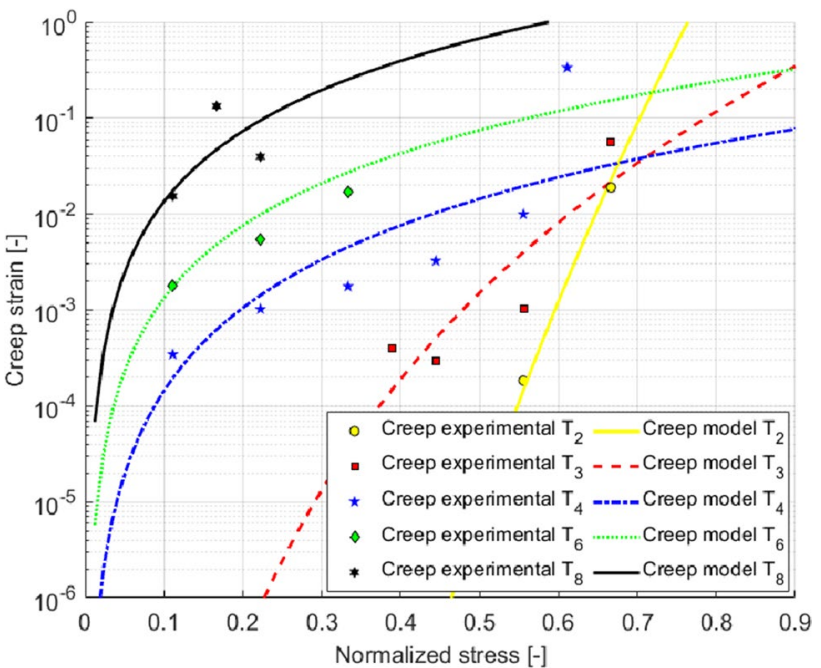

Fig. 8 Comparison of experimental and fitted creep data for different temperature levels at $t=100 \mathrm{~s}$

$\mathrm{T}_{3}-\mathrm{T}_{8}$, so that the high value from $\mathrm{T}_{2}$ is therefore not included. In the same way, the time exponent $m$ is determined by averaging the fitted values.

$\epsilon_{c r}=\sigma^{n} \cdot t^{m} \cdot f(T)$

With the averaged, constant time exponent $m$ and stress exponent $n$, a regression regarding the temperature dependency was carried out. In this case, the constants $A$ for each temperature level were used. Regression pointed out that a power law function in the form of Eq. (3) is most suitable in this case. Therein, the exponent $l$ is the
Fig. 7 Fitted creep model for different temperature levels and experimental data
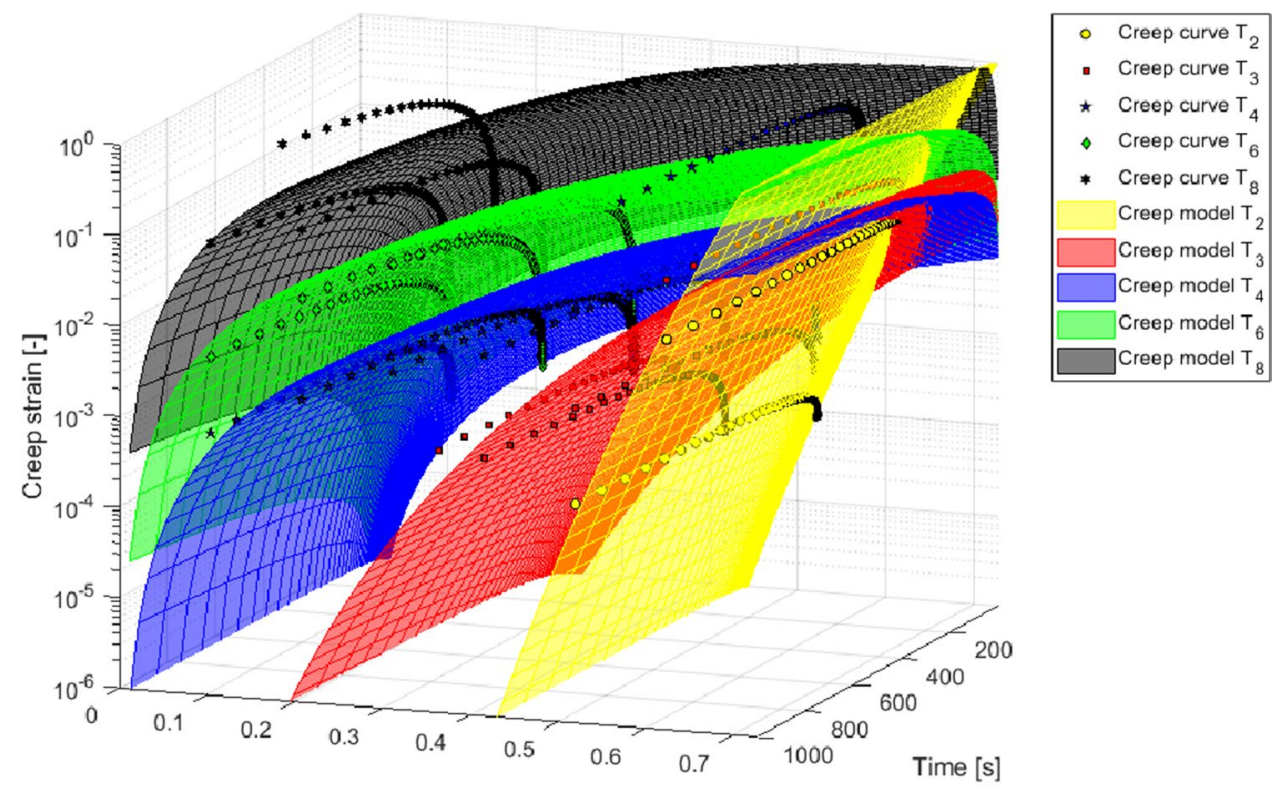

Normalized stress [-] 
fitted temperature exponent and $A_{0}$ is set as constant for all temperature levels.

$f(T)=A_{0} \cdot T^{l}$

$\epsilon_{c r}=A_{0} \cdot \sigma^{n} \cdot t^{m} \cdot T^{l}$

Equation (4) shows the modified, final Norton-Bailey creep law, which is developed by inserting Eq. (3) into the Norton-Bailey creep law in Eq. (1). The constant $A_{0}$ and the exponents regarding stress $(n)$, time $(m)$ and temperature $(l)$ were fitted for the experimentally tested Ti-6Al-4 V base material. The fitted creep model for the temperature $T_{4}$ is illustrated and compared to the experimental creep curves in Fig. 9.

If creep strain in Eq. 4. is deviated with respect to time, the formulation is equivalent to an explicit, time-dependent description of creep strain rate, denoted as time hardening (see Eq. (5)).

$\dot{\epsilon}_{c r}=A_{0} \cdot \sigma^{n} \cdot t^{m-1} \cdot m \cdot T^{l}$

In Fig. 10, the creep strain rate according to the time hardening hypothesis and therefore depending on stress, temperature and time is presented for the fitted creep model for the temperature level $\mathrm{T}_{4}$. The comparison of the fitted model with the experimental data shows a sound correlation.

\section{Simulation model and numerical implementation}

\subsection{Simulation model}

For the thermomechanical simulation of the WAAM process, the commercial software Simufact Welding was used. The finite element simulation model was built according to the experimental boundary conditions and is shown in Fig. 11. Process parameters in Table 4 were used for the fully transient simulation and the welding heat efficiency $\eta$ was set to 0.85 for the CMT welding process, comparable to [33]. The WAAM structure is divided into three layers according to the experimental boundary conditions, whereby the elements are continuously activated by the moving heat source. The used element activation method is called the quite element method [34]. For heat input, a double-ellipsoid model according to Goldak is applied and the thermal boundaries such as contact heat transfer $\alpha\left(1000 \mathrm{~W} / \mathrm{m}^{2} \mathrm{~K}\right)$, convection $h\left(20 \mathrm{~W} / \mathrm{m}^{2} \mathrm{~K}\right)$ and emissivity $\varepsilon(0.55)$ are considered [35]. Additionally, a dwell time of about $62 \mathrm{~s}$ between the layers is taken into account according to the experiment (see Table 5), and the WAAM process is simulated until reaching room temperature.

Regarding the material model, a temperature-dependent, single-phase material database for Ti-6Al-4 V implemented
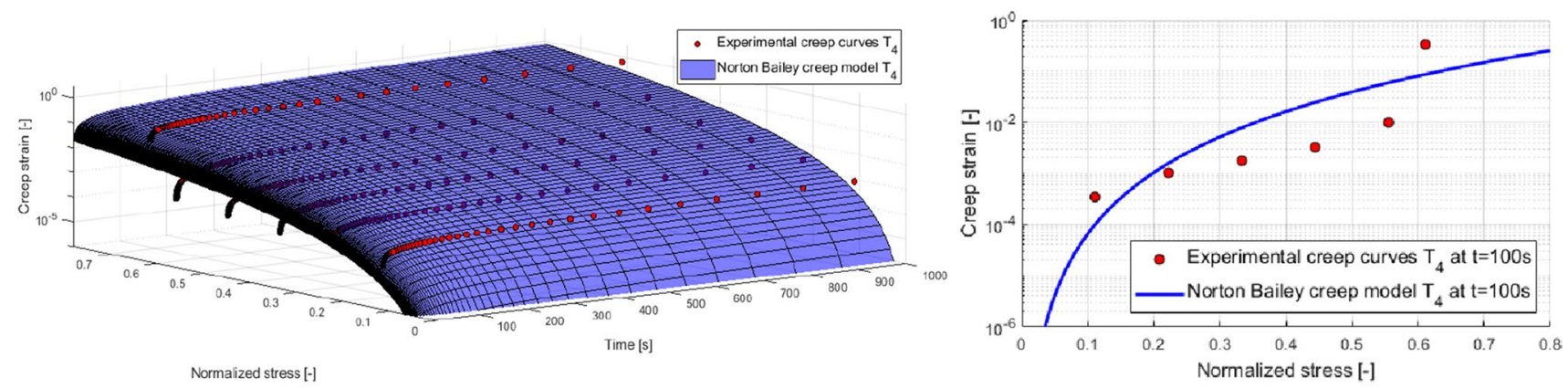

Fig. 9 Final creep model compared to experimental creep curves concerning creep strain
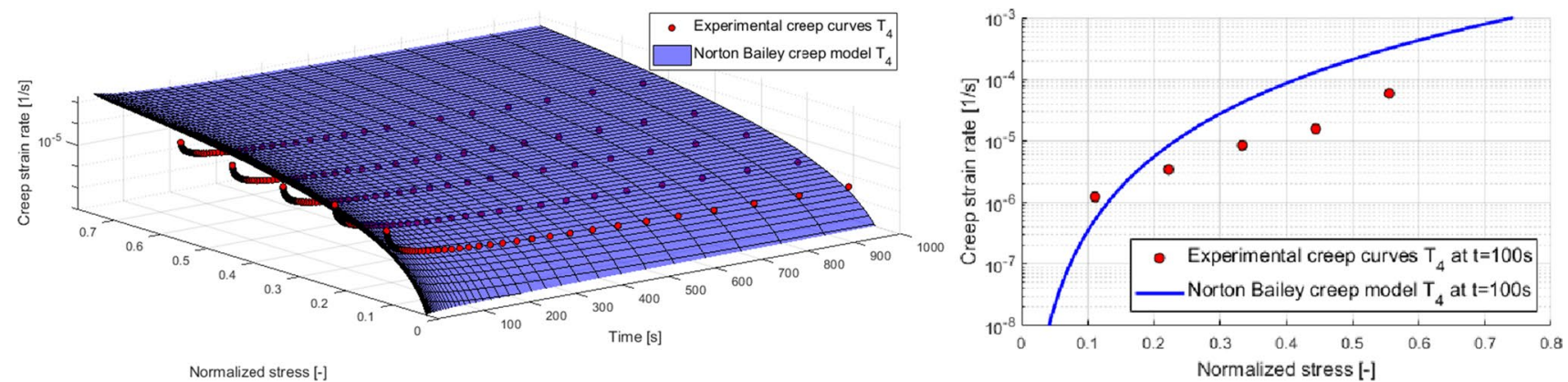

Fig. 10 Final creep model compared to experimental creep curves concerning creep strain rate 

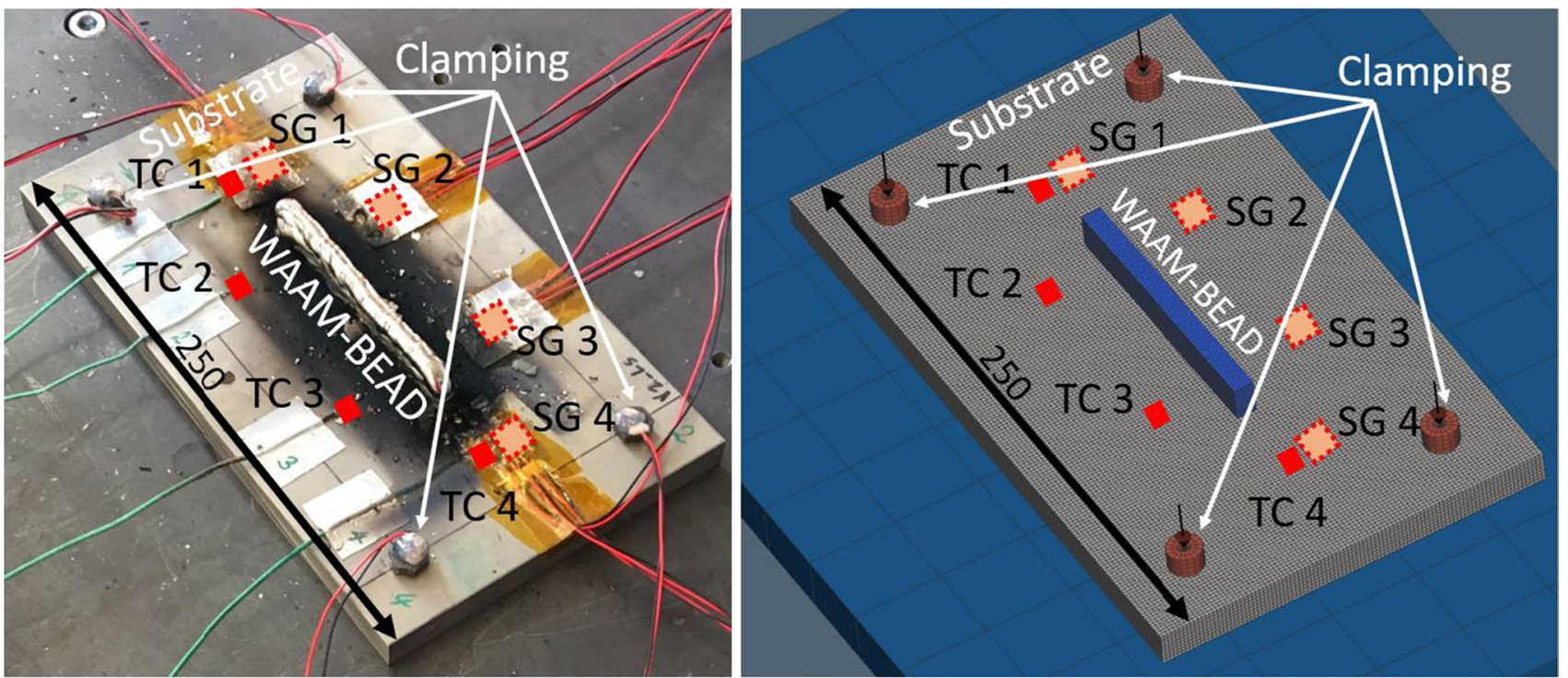

Fig. 11 Experimental WAAM structure after the process and the appropriate simulation model

Table 5 Used WAAM welding parameters

\begin{tabular}{lccl}
\hline Task & Time start (s) & Time end (s) & Dwell time (s) \\
\hline WAAM Layer 1 & 0.0 & 41.6 & 62.2 \\
WAAM Layer 2 & 103.8 & 145.2 & 62.4 \\
WAAM Layer 3 & 207.6 & 249.0 & \\
\hline
\end{tabular}

in the simulation software Simufact Welding 2020 is used. Besides the thermal material properties (conductivity and the heat capacity), the mechanical properties (modulus of elasticity, flow curves, density and coefficient of thermal expansion) are defined as temperature-dependent. Additionally, to consider the hardening or softening of the material during the process, flow curves are defined as dependent on the plastic strain.

\subsection{Implementation of viscoplastic creep model}

By default, no creep properties are considered in the thermomechanical simulation of the WAAM process in the used simulation program Simufact Welding 2020. However, the solver of the simulation programme offers the possibility to define an additional viscoplastic creep material behaviour. In the thermomechanical analysis of welding processes, comparatively large deformations can occur, which leads to non-linearities. These non-linearities are commonly computed using an updated Lagrange method. Regarding plasticity, the hypo-elastoplastic formulation is applied and strain is decomposed as Eq. (6) shows. Due to the summation of elastic strain $\epsilon_{e}$, plastic strain $\epsilon_{p}$ and thermal strain $\epsilon_{T}$, this formulation is specified as additive plasticity. When considering viscoplastic creep behaviour in simulation, creep strain $\epsilon_{c r}$ is added to the formulation (see Eq. (6)) $[34,36]$.

$\epsilon=\epsilon_{e}+\epsilon_{p}+\epsilon_{T}+\epsilon_{c r}$

Material creep properties are defined by the creep strain rate, whereby the appearing creep strain per increment $\Delta \epsilon_{c r}$ is evaluated by multiplying the creep strain rate $\epsilon_{c r}^{\cdot}$ with the normal of the stress surface in the applied yield point model with the equivalent stress $\sigma_{V}$ and occurring stress $\sigma$, see Eq. 7 [34].

$\Delta \epsilon_{c r}=\delta \underline{\dot{\epsilon}_{c r}} \cdot \frac{\delta \underline{\sigma}}{\delta \sigma_{V}}$

There are two possibilities to define and implement the material's viscoplastic creep properties. The first possibility is to directly, explicitly implement a pre-defined creep law by assigning the required model parameters. This is commonly used with time-independent secondary creep laws. In the case of the fitted, time-dependent Norton-Bailey creep law in this study, the creep model is defined using tables. When using the Norton-Bailey creep model in the form of time hardening (see Eq. (5)), the time dependency is critical and will lead to more complex and time-consuming simulations. As an alternative, the Norton-Bailey creep law is defined as time-independent according to strain hardening (see Eq. (8)). Therefore, Eq. (4) is reconfigured for the time and then substituted to Eq. (5). In this case, the creep strain rate no longer depends on time, but on the creep strain itself [37]. 
$\dot{\epsilon}_{c r}=A^{\frac{1}{m}} \cdot \sigma^{\frac{n}{m}} \cdot m \cdot \epsilon_{c r}^{\frac{m-1}{m}} \cdot T^{\frac{l}{m}}$

Finally, to consider the Norton-Bailey creep law according to strain hardening, creep properties were specified in table format containing creep strain rates as a function of stress, temperature and creep strain. The extensive table regarding creep strain rate data for simulation is created for a wide temperature, stress and creep strain range. A python routine is then used to add the specified, tabular creep data to the material data file in simulation. Before the simulation of the WAAM process is started, the input file must be edited and "additive plasticity containing creep strain" has to be activated.

To evaluate if the implementation of the creep model in the simulation was successful, a simplified creep test was modelled. The simulation result was compared to the result calculated from the experimental creep model. The used simulation programme is developed for welding simulations, which is why it is not intended to model a classical tensile creep test. A cuboid with a quadratic cross-section was therefore loaded in compression by a clamping, which is presented in Fig. 12. The ambient temperature is set to the temperature level $\mathrm{T}_{4}$ and the modelled sample was loaded with the resulting, constant, compressive stress level $\sigma_{5}$ in the test area.

The simulated creep strain of the simplified creep test is in close agreement with the experimental data from the

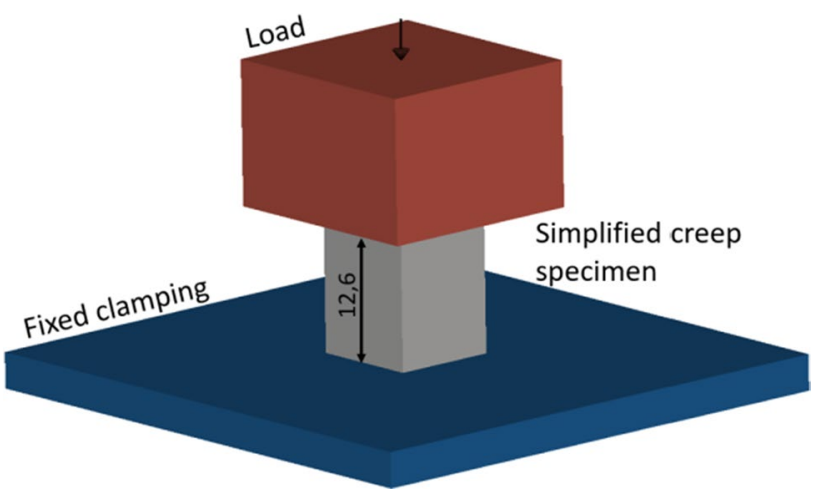

Fig. 12 Simulation model of a simplified creep test implemented creep model. To evaluate the error between simulation and experiment, the mean average percentage error (MAPE) can be used. Thus, the mean average percentage error is evaluated according to Eq. (9), whereby $x_{\text {exp }}$ is the experimental value, $x_{\text {sim }}$ is the simulated value and $n$ is the total number of compared points.

$M A P E=\frac{1}{n} \sum_{i=1}^{n}\left|\frac{x_{\text {exp }, i}-x_{\text {sim }, i}}{x_{\text {exp }, i}}\right| \cdot 100 \%$

The comparison of the simulated and experimental modelled creep strain as a function of time is shown in Fig. 13. Evaluating the MAPE value for this comparison, a relatively small error of about $9 \%$ is found. Because of this, it can be assumed that the creep model was successfully implemented in the simulation software.

\section{Simulation results and comparison to experiment}

\subsection{Temperature profile}

The temperature profile is calculated by the thermomechanical coupled simulation of the WAAM process and compared to the experimentally measured temperature for the thermocouple's location. Figure 14 (left) represents the comparison of experimental and simulated temperature profiles for thermocouple 1 as an example for all thermocouples, which are shown in Fig. 14 (right). The simulated temperature profile and the experimental result are in a sound agreement as can be seen in Fig. 14 (left). A MAPE of about $6 \%$ is calculated for the illustrated thermocouple 1. Overall, the error between simulated and measured temperature profiles, determined by averaging the MAPE values of all thermocouples, is about $12 \%$. Additionally, no significant influence of the implemented creep model on the temperature distribution can be found (see Fig. 14 (left)).

\subsection{Distortion}

Simulated distortion, both with and without implemented creep, is measured after unclamping and compared with
Fig. 13 Comparison of simulated creep test with implemented creep model

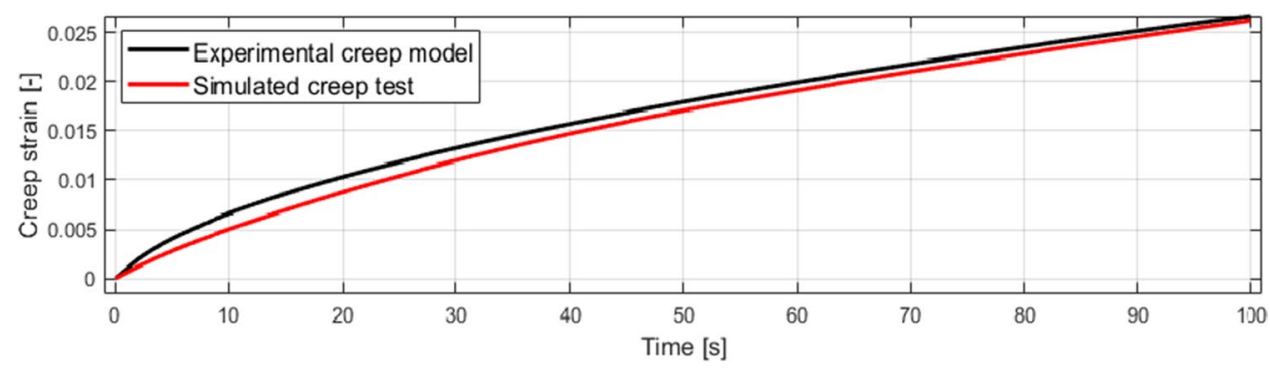


the experimentally measured distortion in order to determine the influence of the implemented creep model and the improvement regarding estimation precision. Therefore, the line-based distortion is measured in longitudinal Y-direction and compared (see Fig. 15).

Implementation of a viscoplastic material behaviour reveals a significant influence on modelled distortion. The comparison of experimentally measured with simulated distortion is presented in Fig. 15. Comparing the average distortion of simulation without implemented viscoplastic creep with the measured data, in general, an overestimation can be observed. The maximum distortion is overestimated by about $12 \%$ and the MAPE is found to be about $21 \%$ (cf. Table 6).

Using the developed viscoplastic creep model in the simulation, the distortion is in close agreement with the WAAM experiment. The comparison of maximum distortion shows a slight underestimation of about $3 \%$, which is acceptable
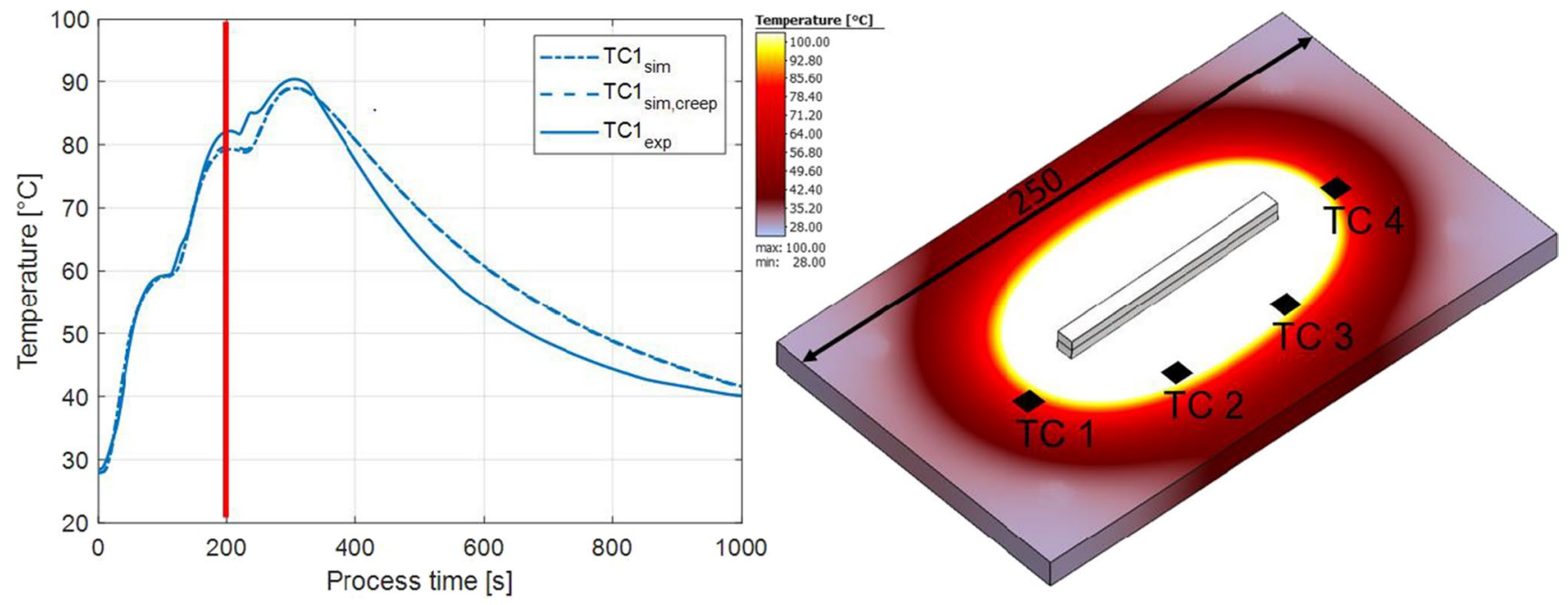

Fig. 14 Juxtaposed temperature profile for TC1 (left) and simulated temperature distribution at $200 \mathrm{~s}$ (right)

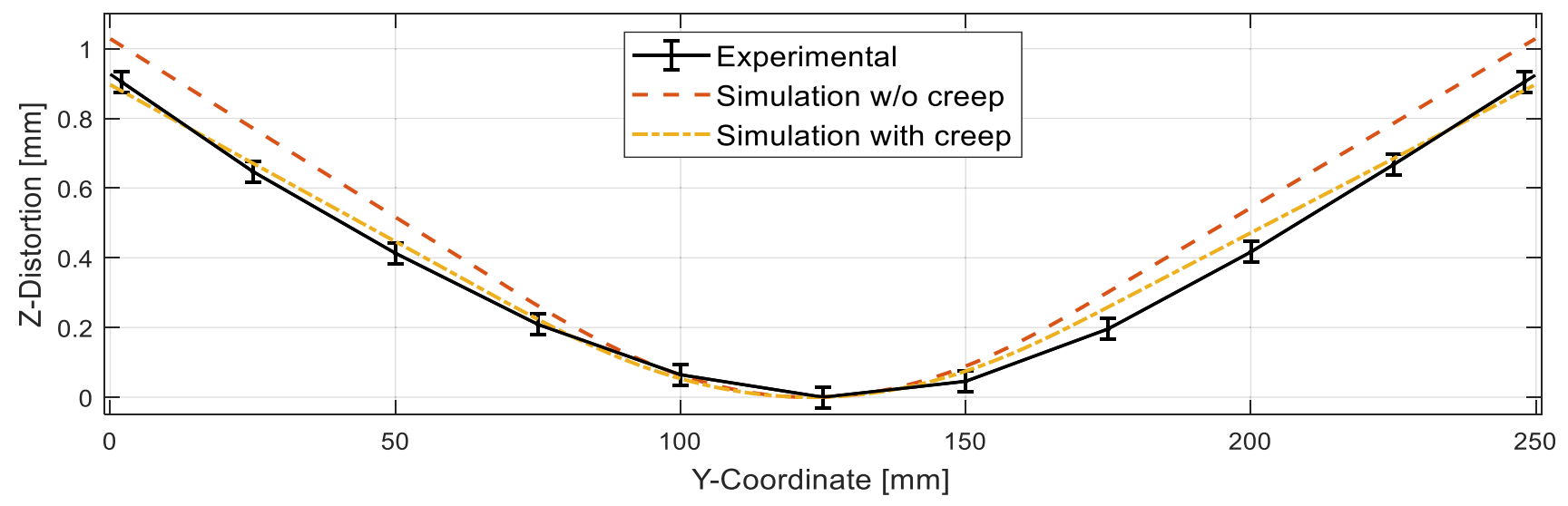

Fig. 15 Comparison of simulated and measured distortion of substrate

Table 6 Comparison of distortion results and deviation for simulation with and w/o creep model

\begin{tabular}{|c|c|c|c|}
\hline & \multicolumn{2}{|c|}{ Z-Distortion in the longitudinal direction } & \multirow{2}{*}{$\begin{array}{l}\text { Mean average } \\
\text { percentage error } \\
\text { (MAPE) }(\%)\end{array}$} \\
\hline & Maximum (mm) & Deviation (\%) & \\
\hline Simulation w/o creep & 1.01 & $+12.2 \%$ & $21.0 \%$ \\
\hline Simulation with creep & 0.88 & $-2.7 \%$ & $13.8 \%$ \\
\hline WAAM experiment & 0.90 & Reference & Reference \\
\hline
\end{tabular}


considering measurement uncertainties. Additionally, the MAPE value decreases by about $34 \%$ from $21 \%$ to about $14 \%$, when a viscoplastic creep behaviour is implemented.

\subsection{Residual stress state}

With the thermomechanical simulation of the WAAM process, it is possible to estimate the residual stress state of the substrate and the WAAM structure itself, during and after the process. First, the residual stress difference, before and after the WAAM process, measured transversal to the welding direction using X-ray diffraction, is compared to the simulation results (see Fig. 16). In doing so, an influence of creep implementation can be observed, in particular in the region of the built WAAM structure, between $Y=-40 \mathrm{~mm}$ and $Y=40 \mathrm{~mm}$. When creep is implemented in the thermomechanical simulation, the estimation error is decreasing. At position $Y=0 \mathrm{~mm}$, the estimation error decreases from about $72 \%$ (no creep implementation) to about $45 \%$ error with an implemented creep model. In general, it can be said that the residual stresses tend to be sufficiently well estimated with the simulation and the implemented creep material behaviour.
The comparison of experimental residual stress difference in longitudinal, welding direction, with simulation results, reveals the same trend as in the transversal direction, with an about $10 \%$ reduced estimation error for the maximum residual stress.

In addition to the residual stress measurement after unclamping, experimental in situ measured stress, at the position of strain gauge 2 , is compared to the simulated stress at this position. The implementation of creep material behaviour reveals an improvement in estimation accuracy of the stress field and the estimation error can be reduced. In Fig. 17, the comparison of experimental with simulated stress in the longitudinal direction at the position of strain gauge 2 as a function of time is shown. The mean average percentage error can be reduced by $14 \%$ in longitudinal and by about $21 \%$ in transversal direction by implementing the discussed viscoplastic creep model (see Table 7).

Finally, the error between measured and simulated stress after $800 \mathrm{~s}$ can be decreased from about 72 to about $45 \%$ implementing creep material behaviour in thermomechanical simulation (see Table 7). Thus, it is shown that the implementation of creep is strongly recommended for the thermomechanical simulation of the WAAM process.
Fig. 16 Residual stress difference normal to welding direction (transversal, $\mathrm{X}$-direction)
Fig. 17 Comparison of stress at the position of strain gauge 2 in longitudinal welding direction
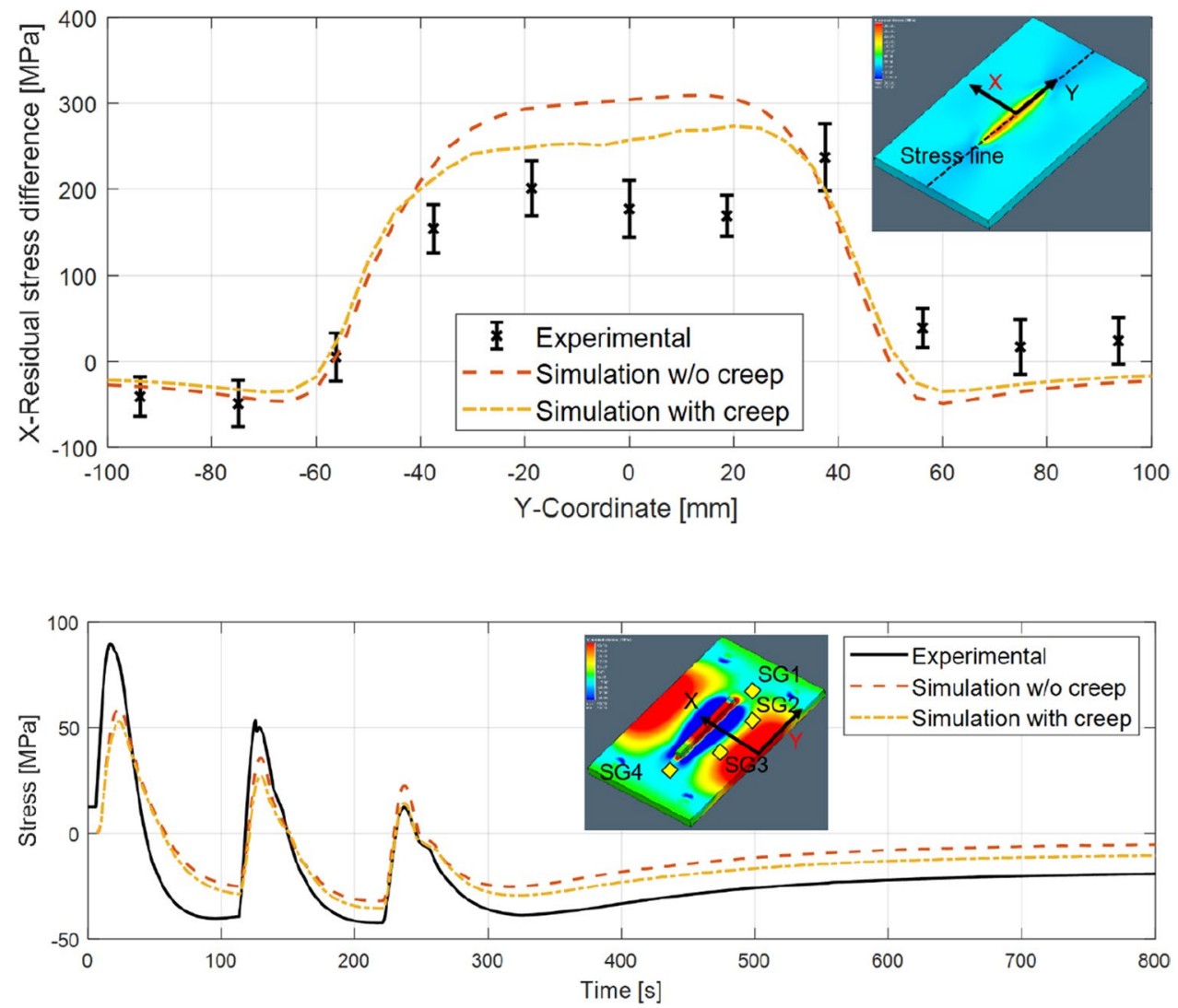
Table 7 Mean average percentage error and stress after $800 \mathrm{~s}$ in the longitudinal direction at SG2

\begin{tabular}{llll}
\hline & $\begin{array}{l}\text { MAPE of longi- } \\
\text { tudinal stress at } \\
\text { SG2 }(\%)\end{array}$ & \multicolumn{2}{l}{ Stress after $t=800 \mathrm{~s}$} \\
\cline { 3 - 4 } & Stress (MPa) & Deviation (\%) \\
\hline $\begin{array}{c}\text { Simulation w/o } \\
\text { creep }\end{array}$ & $30.2 \%$ & -5.4 & $+71.9 \%$ \\
$\begin{array}{c}\text { Simulation with } \\
\text { creep }\end{array}$ & $26.1 \%$ & -10.6 & $+44.8 \%$ \\
$\begin{array}{c}\text { WAAM experi- } \\
\text { ment }\end{array}$ & Reference & -19.2 & Reference \\
\hline
\end{tabular}

\section{Summary and conclusion}

In this study, a viscoplastic creep model for the-in WAAM processes-commonly used alloy Ti-6Al-4 V was developed. Numerous creep tests in a wide temperature and stress range were carried out. A short-term creep model according to Norton-Bailey is used to fit the experimental creep data. Subsequently, the model has been effectively implemented in the simulation, using a table input. In order to evaluate the influence of the model implementation, simulations, with and without consideration of creep, were carried out for a three-layer WAAM structure. Based on a comparison of the simulated temperature field, distortion and residual stress state with experimental data for the substrate of the three-layer WAAM structure, the following conclusions can be drawn:

- Norton-Bailey creep model can be used to describe short-term creep behaviour as a function of stress, temperature and time for Ti-6Al-4 V.

- The implementation of the viscoplastic creep model does not affect temperature profile, whereby a sound agreement with an overall error of about $12 \%$ comparing both simulations, with and without creep, to the experimentally measured temperatures can be observed.

- Considering creep behaviour in simulation majorly influences the estimation of distortion. By implementing the fitted creep model, the error between simulated distortion and experimental data can be reduced by about $34 \%$, which proofs the importance of considering creep in the simulation of the WAAM process.

- Residual stress estimation accuracy is improved with the use of creep in simulation compared to the standard simulation. Simulation with creep reveals a decrease of mean average percentage error by about $14 \%$ regarding residual stresses in welding direction. Hence, it is of utmost importance to consider creep in the simulation of the WAAM process.
To sum up, the results presented in this study demonstrate a major impact of considering creep in the simulation of the WAAM process on estimation accuracy of residual stresses and distortion. A similar trend in the improvement of distortion estimation can be found by implementing a stress relaxation temperature in the thermomechanical simulation in [25]. The established creep model for Ti-6Al-4 V is fitted for the base material and validated for one process parameter set in this study. Ongoing research is on the applicability of the creep model for different WAAM process parameter sets and different WAAM processes. Future work will focus on investigations regarding the creep behaviour of material out of the WAAM structure and the influence of interpass layer and preheating temperature. Moreover, the focus will be laid on the influence of the number of layers and the simulation of more complex, near-net-shape structures, like crossings or L-shapes.

Funding Open access funding provided by Montanuniversität Leoben Special thanks are given to the Austrian Research Promotion Agency (FFG; project number 32765288), who funded the research project with funds of the Federal Ministry for Climate Action, Environment, Energy, Mobility, Innovation and Technology (bmk) and the Federal Ministry for Digital and Economic Affairs (bmdw).

\section{Declarations}

Competing interests The authors declare no competing interests.

Open Access This article is licensed under a Creative Commons Attribution 4.0 International License, which permits use, sharing, adaptation, distribution and reproduction in any medium or format, as long as you give appropriate credit to the original author(s) and the source, provide a link to the Creative Commons licence, and indicate if changes were made. The images or other third party material in this article are included in the article's Creative Commons licence, unless indicated otherwise in a credit line to the material. If material is not included in the article's Creative Commons licence and your intended use is not permitted by statutory regulation or exceeds the permitted use, you will need to obtain permission directly from the copyright holder. To view a copy of this licence, visit http://creativecommons.org/licenses/by/4.0/.

\section{References}

1. Herzog D, Seyda V, Wycisk E et al (2016) Additive manufacturing of metals. Acta Mater 117(3):371-392. https://doi.org/10.1016/j. actamat.2016.07.019

2. Prakash KS, Nancharaih T, Rao VS (2018) Additive manufacturing techniques in manufacturing -an overview. Mater Today: Proc 5(2):3873-3882. https://doi.org/10.1016/j.matpr.2017.11.642

3. Kruth J-P, Leu MC, Nakagawa T (1998) Progress in additive manufacturing and rapid prototyping. CIRP Ann 47(2):525-540. https://doi.org/10.1016/S0007-8506(07)63240-5

4. Singh SR, Khanna P (2020) Wire arc additive manufacturing (WAAM): a new process to shape engineering materials. Mater 
Today: Proc 67(5-8):1191. https://doi.org/10.1016/j.matpr.2020. 08.030

5. Rodrigues TA, Duarte V, Miranda RM et al (2019) Current status and perspectives on wire and arc additive manufacturing (WAAM). Materials (Basel) 12(7):1121. https://doi.org/10.3390/ma12071121

6. Tofail SAM, Koumoulos EP, Bandyopadhyay A et al (2018) Additive manufacturing: scientific and technological challenges, market uptake and opportunities. Mater Today 21(1):22-37. https:// doi.org/10.1016/j.mattod.2017.07.001

7. Bambach M, Sizova I, Sydow B et al (2020) Hybrid manufacturing of components from Ti-6Al-4V by metal forming and wire-arc additive manufacturing. J Mater Process Technol 282(4):116689. https://doi.org/10.1016/j.jmatprotec.2020.116689

8. Meiners F, Ihne J, Jürgens P et al (2020) New hybrid manufacturing routes combining forging and additive manufacturing to efficiently produce high performance components from Ti-6Al-4V. Procedia Manufacturing 47:261-267. https://doi.org/10.1016/j. promfg.2020.04.215

9. Angrish A (2014) A critical analysis of additive manufacturing technologies for aerospace applications. 201 IEEE Aerospace Conference. IEEE, New Jersey, pp 1-6

10. Uriondo A, Esperon-Miguez M, Perinpanayagam S (2015) The present and future of additive manufacturing in the aerospace sector: a review of important aspects. Proc Instit Mech Eng G J Aerospace Eng 229(11):2132-2147. https://doi.org/10.1177/ 0954410014568797

11. Szost BA, Terzi S, Martina F et al (2016) A comparative study of additive manufacturing techniques: residual stress and microstructural analysis of CLAD and WAAM printed Ti-6Al-4V components. Mater Des 89(6):559-567. https://doi.org/10.1016/j.matdes. 2015.09.115

12. Wohlbier $\mathrm{T}$ (2017) Residual stress characterization and control in the additive manufacture of large scale metal structures. Materials Research Forum LLC. pp 455-460

13. Jafari D, Vaneker THJ, Gibson I (2021) Wire and arc additive manufacturing: opportunities and challenges to control the quality and accuracy of manufactured parts. Mater Des 202(1):109471. https://doi.org/10.1016/j.matdes.2021.109471

14. Stender ME, Beghini LL, Sugar JD et al (2018) A thermalmechanical finite element workflow for directed energy deposition additive manufacturing process modeling. Addit Manuf 21(6):556-566. https://doi.org/10.1016/j.addma.2018.04.012

15. Rong $Y, X u J$ J, Huang $Y$ et al (2018) Review on finite element analysis of welding deformation and residual stress. Sci Technol Weld Joining 23(3):198-208. https://doi.org/10.1080/13621718.2017.1361673

16. Ding J, Colegrove P, Mehnen J et al (2011) Thermo-mechanical analysis of wire and arc additive layer manufacturing process on large multi-layer parts. Comput Mater Sci 17:23. https://doi.org/ 10.1016/j.commatsci.2011.06.023

17. Michaleris P (2013) Modelling welding residual stress and distortion: current and future research trends. Sci Technol Weld Join 16(4):363-368. https://doi.org/10.1179/1362171811Y.0000000017

18. Song X, Feih S, Zhai W et al (2020) Advances in additive manufacturing process simulation: residual stresses and distortion predictions in complex metallic components. Mater Des 193(1):108779. https://doi.org/10.1016/j.matdes.2020.108779

19. Neugebauer F, Keller N, Ploshikhin V et al (2014) Multi scale FEM simulation for distortion calculation in additive manufacturing of hardening stainless steel. International Workshop on Thermal Formingand Welding Distortion, Bremen
20. DebRoy T, Wei HL, Zuback JS et al (2018) Additive manufacturing of metallic components - process, structure and properties. Prog Mater Sci 92(5):112-224. https://doi.org/10.1016/j.pmatsci. 2017.10.001

21. Megahed M, Mindt H-W, N'Dri N et al (2016) Metal additivemanufacturing process and residual stress modeling. Integr Mater Manuf Innov 5(1):61-93. https://doi.org/10.1186/ s40192-016-0047-2

22. Lu X, Lin X, Chiumenti M et al (2018) Finite element analysis and experimental validation of the thermomechanical behavior in laser solid forming of Ti-6Al-4V. Addit Manuf 21(3):30-40. https://doi.org/10.1016/j.addma.2018.02.003

23. Denlinger ER, Heigel JC, Michaleris P (2015) Residual stress and distortion modeling of electron beam direct manufacturing Ti-6Al-4V. Proc Instit Mech Eng B J Eng Manuf 229(10):18031813. https://doi.org/10.1177/0954405414539494

24. Denlinger ER, Heigel JC, Michaleris P et al (2015) Effect of interlayer dwell time on distortion and residual stress in additive manufacturing of titanium and nickel alloys. J Mater Process Technol 215(14):123-131. https://doi.org/10.1016/j.jmatprotec.2014.07. 030

25. Denlinger ER, Michaleris P (2016) Effect of stress relaxation on distortion in additive manufacturing process modeling. Addit Manuf 12(2):51-59. https://doi.org/10.1016/j.addma.2016.06.011

26. Norton FH (1929) The creep of steel at high temperatures. McGraw-Hill book Company, Inc., Madison

27. Bailey RW (1935) The utilization of creep test data in engineering design. Proc Inst Mech Eng 131(1):131-349. https://doi.org/10. 1243/PIME_PROC_1935_131_012_02

28. Valbruna Edel Inox GmbH (2021) Data sheet: Valbruna GR 5 / Ti Gr. 5 / Ti-6Al-4V. Valbruna Edel Inox GmbH, Dormagen

29. voestalpine Böhler Welding GmbH (2019) Data sheet: 3Dprint AM Ti-5. voestalpine Böhler Welding GmbH, Kapfenberg

30. 3T Additive Manufacturing Ltd. (2021) Data sheet: Titanium Ti6Al4V. 3T Additive Manufacturing Ltd., Newbury

31. ASTM E139-11 (2018) Test methods for conducting creep, creeprupture, and stress-rupture tests of metallic materials. ASTM, West Conshohocken

32. May DL, Gordon AP, Segletes DS (2013) The application of the Norton-Bailey law for creep prediction through power law regression. Proceedings of the ASME Turbo Expo 2013: Turbine Technical Conference and Exposition. Structures and Dynamics 7A(7A). https://doi.org/10.1115/GT2013-96008

33. Ding J, Colegrove P, Mehnen J et al (2014) A computationally efficient finite element model of wire and arc additive manufacture. Int J Adv Manuf Technol 70(1-4):227-236. https://doi.org/ 10.1007/s00170-013-5261-x

34. MSC.Software GmbH (2020) Documentation: Marc Volume A: theory and user information. MSC.Software GmbH, München

35. Goldak JA, Akhlaghi M (2005) Computational welding mechanics. Springer Science+Business Media Inc, Boston

36. Lindgren L-E (2007) Computational welding mechanics: thermomechanical and microstructructural simulations. Woodhead Publishing in materials. CRC Press, Boca Raton

37. Ee Magd (2009) Hochtemperatur-Werkstofftechnik: Festigkeit, Deformation und Bruch, 2., überarb. Aufl. Berichte aus der Werkstofftechnik. Shaker, Aachen

Publisher's note Springer Nature remains neutral with regard to jurisdictional claims in published maps and institutional affiliations. 